\title{
El escritor uruguayo y la imaginación. Una tragedia bárbara de Copi en argentino
}

\begin{abstract}
Resumen
Escrita en la variedad rioplatense del idioma español, en Francia, durante la última dictadura argentina (1976-1983), La sombra de Wenceslao (1978) acciona un dispositivo teatral que propicia la interrogación sobre el funcionamiento de la producción atópica (Barthes) de Copi en la tradición literaria argentina reformulada en el fin de siglo. La acción del gaucho uruguayo Wenceslao despliega un sistema de relaciones que desarma los agenciamientos nacionales con lo animal y lo territorial (Foucault, Rancière); territorializado hacia 1910 como arquetipo nacional (Lugones, Rojas), ese sujeto desclasificado de la pre-modernidad argentina vuelve desterritorializado por Copi con una imaginación desplazada del canon, no asimilable a las revisiones principales de aquella territorialización (Martínez Estrada, Borges, Lamborghini). La circulación de voces y cuerpos externos a la norma nacional en $L a$ sombra de Wenceslao puede leerse como realización teatral de una atópica poesía gauchesca, absuelta de la patria y del género, contemporánea del derrumbe del Estado bajo la violencia política y económica del último cuarto del siglo.
\end{abstract}

Palabras claves

canon; cuerpo; gaucho; nacionalidad; naturaleza; teatro; tradición.

\begin{abstract}
Written in rioplatense dialectal variety of Spanish language, in France, during last Argentine dictatorship (1976-1983), La sombra de Wenceslao (1978) activates a theatrical device that foster questions about functioning of the atopic (Barthes) production of Copi in Argentine literary tradition, which is reformulated at the end of the century. The action of Uruguayan gaucho Wenceslao displays a system of relations that dismantles national agency with the animal and the territorial (Foucault, Rancière); this disqualified subject of Argentine premodernity, territorialized like a national archetype around 1910 (Lugones, Rojas), returns un-territorialized by Copi with an imagination displaced of canon, non comprehensible by major revisions of that territorialization (Martínez Estrada, Borges, Lamborghini). Voices and bodies circulate out of national standard in La sombra de Wenceslao; it can be read as theatrical realization of an atopic gauchesca poetry, absolved from homeland and
\end{abstract}


genre/gender, contemporary to collapse of the state under political and economic violence at the last quarter of XX century.

Keywords

canon; body; gaucho; nationality; nature; theatre; tradition.

\section{Profanadora risa sin estilo}

Seudónimo de Raúl Natalio Roque Damonte Botana (Buenos Aires, 1939París, 1987), Copi dispara la imaginación de una figura de autor que no cabe en ningún emplazamiento, y firma una obra que -abarcando dibujo, historieta, relato, novela, guión teatral, actuación- no se deja normalizar por contextos culturales (v. gr. exilio del peronismo, mayo del 68, dictaduras argentinas, enfermedad de sida) ni categorías institucionales como teatro, literatura o literatura argentina. ${ }^{1}$ Leer a Copi es una acción donde la cultura enfrenta sus propios límites, prejuicios y lugares comunes. Tales tensiones pautan la entrevista a Copi que en 1982 realiza Tcherkaski; el malentendido que provoca su pretensión de develar el presunto misterio apodado Copi puede ser un buen ingreso en esta anormalidad creadora que desafía los protocolos críticos. A la manera de un predicador pos-freudiano ("Digo lo que dicen los psicólogos... no te enojes conmigo"), el entrevistador persigue al entrevistado con preguntas como “¿Siempre fuiste homosexual?”, “¿Te hubiera gustado tener un hijo?”, “¿Te hubiera gustado ser mujer?”, “¿Vivís molesto?”, “¿Tenés dinero?”. Luego de imponer el tema del miedo -que Copi relativiza con "qué angustia tienen los argentinos" y propone que los que tienen miedo atraviesen "el océano en balsa (se ríe)"- Tcherkaski da pie a lo que queremos leer a partir de la potencia anómala de Copi: “El problema no soy yo, es

\footnotetext{
${ }^{1}$ Una conceptualización interesante del seudónimo y los datos biográficos puede verse en el prólogo de María Moreno en Obras (Tomo I) de Copi (7-31).
} 
CATEDRal Tomada: Revista literaria latinoamericana / Journal of Latin American Literary Criticism

El escritor uruguayo y la imaginación. Una tragedia bárbara de Copi en argentino

todo el país" (Tcherkaski 65). La tensión dialógica que genera un entrevistador que pretende hablar por todo el país y descifrar al entrevistado replica las dificultades que, al menos hasta comienzos del siglo XXI, la voz poética de Copi ha suscitado en la capacidad de recepción del campo cultural argentino.

La idea misma de nación, ese todo el país, lo argentino, es el "problema" en el que Copi no entra: siempre está saliendo, en errancia y profanación. Respuestas en fuga como "No sé qué responderte; yo nunca pensé de ese modo" (80) sintetizan la disrupción entre Copi y los modos consensuados de leer. Al entrevistado le quedaría la posibilidad de modular la salida del Bartleby de Melville: Preferiría no hacerlo, no explicar mi obra o mi lugar de nacimiento, ni si me irrita o angustia el "tema de la homosexualidad" o el de "ser argentino". Para la crítica institucional Copi es un problema (o peor: ni siquiera lo es) porque el nomadismo sostiene su figura de autor, desterritorializado de géneros $\mathrm{y}$ tradiciones, que reúne y mezcla lo que la modernidad separa en categorías y expone como especialidades en el mercado. El nombre falso que dirige el imaginario, Copi, atraviesa las funciones de autor, actor, dibujante, narrador, personaje, espectador. ${ }^{2}$ Semejante tránsito subjetivo nos deja mudos ante la comedia de muerte que vamos a leer.

Como preferiríamos leerla una y otra vez, para intentar decir la productiva mudez que provoca, reutilizamos el tópico del escritor argentino y la tradición en busca de las preguntas que nos hace el gaucho movilizado en La sombra de Wenceslao. Aunque Borges en el centro del XX haya abierto el jardín argentino a los árboles y arbustos de "toda la cultura occidental", el basural de Copi atraviesa cultura y estilo, lo primero que no se tiene, que no se quiere cultivar: "Quiero que el público vea una obra mía y no reconozca nada de lo que ha visto anteriormente

\footnotetext{
${ }^{2}$ No solo se ubica como "el primer espectador" de sí mismo (Tcherkaski 34,85), también sube al escenario al último espectador que imagina: Cyrille, el protagonista de Una visita inoportuna, moribundo de sida -"símbolo de Copi" en la aplanadora de Rosenzvaig (107)-, hacia el final responde al Periodista-mudo la única pregunta que ha hecho, si "debe quedarse": "Cuento imperativamente con usted. Es el único neófito en esta comedia de la muerte, y también nuestro último espectador" (Copi, Teatro 215).
} 
(...). Porque yo no tengo estilo, no cultivo un estilo" (Tcherkaski 86). El país de Copi no cabe en la dicotomía local-universal, no es lugar sino tránsito, intimidad en movimiento; no se define por la identidad ni la pertenencia, sino por la expulsión, el margen, el pasaje. ¿Cómo leer a un artista sin lugar que no cultiva un estilo? Semejante desafío abre la posibilidad de mantener la inestabilidad entre risa y tragedia, realizar ese cambio radical de las formas que es el humor, asumiendo el chiste profanador que acciona Copi.

En 1973, Barthes marca distancia con una mitología menor, la que nos hace creer que el placer del texto es una idea de derecha, que expide hacia la izquierda todo lo que es abstracto, incómodo, político; y en la izquierda, por moralidad, todo "residuo de hedonismo" aparece como sospechoso, desdeñable. Pero el placer no es un elemento del texto, no depende de una lógica del entendimiento y la sensación: es una deriva, algo a la vez revolucionario y asocial, que no puede ser asumido por ninguna colectividad ni idiolecto; es escandaloso no por inmoral sino porque es atópico, no ligado a ningún lugar preciso (Barthes, El placer 37-38). El placer nómada del texto no tiene acepción ideológica, desborda la unidad moral que la sociedad exige del producto humano. Las fuerzas contrarias no están en estado de represión sino en devenir: nada es verdaderamente antagonista, todo es plural (51-52). ${ }^{3}$ Visto desde la institución literaria, el teatro de Copi desnuda la impertinencia monológica de la crítica, su necesidad de bibliotecas y tradiciones. "Nunca leí nada de Artaud", replica al intento clasificatorio de Tcherkaski (29), lo desconcierta con "No leo, no voy al cine, no voy al teatro (se ríe)" (la risa que acota el entrevistador intenta cargar de ironía explicativa una negación que no tenía por qué tenerla), provoca la demanda de un sentido (“Eso, ¿cómo lo explicarías vos? ¿Por qué?”) y responde con la

\footnotetext{
3 Átopos -refinará Barthes en 1977- es la calificación dada a Sócrates por sus interlocutores, que designa el modo en que el ser amado es reconocido por el sujeto amoroso (el protagonista de los Fragmentos de un discurso amoroso): "de una originalidad incesantemente imprevisible", "me fascina" y "no puedo clasificarlo puesto que es precisamente el Único", imagen singular que responde a "la especificidad de mi deseo" (Barthes, Fragmentos 42).
} 
CATEDRAL TOMADA: Revista literaria latinoamericana / Journal of Latin American Literary Criticism

El escritor uruguayo y la imaginación. Una tragedia bárbara de Copi en argentino

simpleza de la profanación: "porque en lo único que pienso es en modificarlo" (31).

El desafío crítico está antes del acostumbrado movimiento de buscar esa modificación en la dupla tradición/vanguardia; lo que se modifica es la misma dupla y la lógica que la sostenía. De ahí que, a la insistencia de Tcherkaski ("De los franceses, ¿nada más?”) y sus intentos de filiación política con la izquierda europea, Copi anteponga el aprendizaje menor y porteño de la caricatura que culminará en La mujer sentada (la tira semanal que publicó en Le Nouvel Observateur desde 1964 durante diez años): “qué sabrán ellos de la influencia que puedo tener de Landrú o de Lino Palacio?” (27). Algo de ese humor de apariencia simple convertible en magistral, que Copi copiaba de Oski en sus tiras porteñas entre 1955 y 1962, perdura en la dramaturgia por la que empezará a ser reconocido luego del escándalo de Eva Perón en 1970 (con la profanación de desasignar los géneros al punto de que un hombre interprete a la primera dama), y asomará en varios gags de Largui y otros pases de los que abundan entre la cómica prepotencia de Wenceslao. Tanto como las tiras y las narraciones, las tragedias teatrales de Copi merodean la risa como "instante de peligro en que las cosas dejan de ser lo que eran y se transforman en otras", accionan el humor como "cambio radical de las formas naturales" y "exterioridad respecto de sí" (Link, "Las fuentes").

Al contrario de la caza hermenéutica practicada por cierta crítica -"Copi es una legión de símbolos a descifrar" (Rosenzvaig 70)- podemos no reterritorializar tan pronto y sostener su exigencia contra el desciframiento y la interpretación. No hay transgresión de algún tipo de narración o estética, porque Copi suspende toda adhesión y no tiene en cuenta lo que sería una tradición a transgredir. Si cabe la tradición en su sistema, es en tanto "relación con un inapropiable", como uso libre, separado del derecho y la propiedad, como profanación en el sentido en que la elogia Agamben: "el paradigma de una imposibilidad de usar" (que niega el uso de hecho bajo la sola autoridad del derecho de propiedad) alcanza su cumplimiento entre los consumidores de las sociedades de masas, "infelices" no 
solo porque consumen "objetos que han incorporado su propia imposibilidad de ser usados, sino también -y sobre todo- porque creen ejercer su derecho de propiedad sobre ellos, porque se han vuelto incapaces de profanarlos" (Agamben, "Elogio" 108-109). La risa profanadora desacraliza la mitología argentina, el modelo masculino, el teatro nacional: altera las formas naturales (que son culturales).

¿Cómo profanar con Copi sin interpretarlo? Este paseo por su paisaje trans-criollista buscará el placer del texto, la dislocación que Copi expone con sencillez grotesca: "Hacer de la muerte algo de morirse de risa" (Tcherkaski 41). La sombra de Wenceslao termina como tantas piezas de Copi, con la mayoría de los personajes muriendo, siguiendo la consigna de Raulito en octosílabos cuando, para acabar Cachafaz (1981), responde al "Y yo aquí me estoy muriendo" de Cachafaz: "Yo también, muramosnós, / se está levantando el viento" (Copi, Cachafaz / La sombra 74). Antes de morir, los personajes con su acción han dicho riamosnós, como tentando a buscar el placer que persiste en el espectador. Y si el placer es atópico, probaremos tensarlo con ese lugar impreciso que tantos han querido delimitar en torno a la unidad moral o la acepción ideológica, el de la máxima interpretabilidad privada y el mínimo entendimiento público: lo argentino. Por ese territorio deambula Wenceslao para no quedarse ni meramente exiliarse, volviendo inapropiable lo que desde 1910 era objeto de deseo de la literatura nacional (tener una tradición propia, apropiada). Al poner en acto plurales unidades del imaginario cultural argentino (v. gr. Eva Perón, Borges, Río de la Plata, gaucho, tango), devuelve a la tradición del siglo XX la posibilidad de profanar el canon y reír durante la catástrofe que lo atraviesa. 
CATEDRAL TOMADA: Revista literaria latinoamericana / Journal of Latin American Literary Criticism El escritor uruguayo y la imaginación. Una tragedia bárbara de Copi en argentino

\section{II. ¿Qué catzo me interesa!}

Copi denigra nuevamente a su patria. (Periódico argentino, sobre La Copa del Mundo de Copi)

Lo atópico, lo plural, un uso menor de la lengua nacional, transversal a su idiolecto prestigioso (el artificio literario de oralidad rioplatense) conforman las intensidades de aparición de lo argentino en el teatro de Copi que leeremos. Lo que allí repercute de la gauchesca viene menos de su tradición política y social que de su repetición industrial en el criollismo, la explotación de los restos del género en el revival de gauchos y guapos del circo criollo, el sainete, el cine, la radio, la televisión. ${ }^{4} \mathrm{El}$ dispositivo teatral reubica géneros y tópicos prestigiosos del debate nacional, los desplaza a ningún lugar preciso, en transversalidad ajena a toda acepción ideológica. En Cachafaz y La sombra de Wenceslao se realiza una deriva que evade las ideas dominantes en torno a la colectividad y el idiolecto rioplatenses. ¿Cómo desbordarían esos atípicos sujetos de Copi la unidad moral que la comunidad ha exigido del gaucho luego de hacerlo desaparecer? Desde que, según la anécdota autobiográfica, la emergencia del peronismo provocó el escape del niño Copi por un balcón para propiciar la huida familiar al Uruguay, "poco antes del 17 de octubre de 1945" (Copi, Obras 349), la Argentina quedó como el recuerdo nefasto de una fuga: “¡Cómo no me voy a acordar de la Argentina! Cualquiera se acuerda del infierno, es de lo que uno más se acuerda"

\footnotetext{
${ }^{4}$ Lejos de la métrica sentenciosa del Martín Fierro de J. Hernández y de los prestigiosos Santos Vega de B. Mitre, R. Obligado y H. Ascasubi (pero cerca de su "Refalosa"), las voces de Cachafaz o Wenceslao remedan módulos expresivos del criollismo que fueron aceptados por el repertorio gestual de la política en la formación de la Argentina moderna entre 1880 y 1910, como ha estudiado Prieto (El discurso 162-163, 172, 176, 183). Algunas resonancias de sus análisis circulan por la escena de Copi, como el debate sobre el idioma nacional (implicado en las opciones lexicales de ambas piezas), lo gauchesco como "superficie aglutinante de usos expresivos correspondientes a una tipología social" (sobre la cual genera severos cambios), la manipulación comercial y la perniciosa influencia de los folletines criollistas, o el tópico de la redención del criollo trabajador (radicalmente invertido, como veremos, por los personajes de Copi).
} 
(Tcherkaski 67). Copi desarma la pregunta que le adjudica el valor del "compromiso", equipara el "problema argentino" con el "problema homosexual" como parejos inventos de "ustedes", y pasea por las ramas mezcladas de su árbol familiar: "Lo que vos me pedís es que diga a la Argentina que tengo un problema. No tengo ningún problema con la Argentina. (...). Mi abuela era española, mi abuelo, uruguayo; tengo un abuelo entrerriano, una bisabuela judía, dos bisabuelas que eran indias. ¡Qué catzo me interesa ser argentino! ¿A quién le va a importar ser argentino?" (68-69). ${ }^{5}$

Las disonancias de esta entrevista marcan un doblez afortunadamente imposible de aplanar: la distancia entre, por un lado (el de la acción teatral y narrativa), la peculiar antropología que interviene sobre configuraciones actuales de la patria y el lenguaje y, por otro (el lado recto y sedentario, lo inamovible), la biopolítica nacional del Estado moderno. Sobre la soberanía en que se basa el mapa mundial de la jurisprudencia moderna, Agamben observa que, con las declaraciones de derechos humanos posteriores a las revoluciones burguesas europeas, la pregunta por lo nacional (“¿Qué es francés? ¿Qué es alemán?”) "empieza a convertirse en una cuestión política esencial", hasta que "con el nacionalsocialismo, la respuesta a la pregunta ‘¿Quién y qué es alemán?’ (y por ende también: ‘¿Quién y qué no lo es?’) coincide sin más con la tarea política suprema" (Agamben, "Política" 6, 8). A preguntas semejantes Copi permite no responder, hablar de otras cosas, no pautadas ni previstas por quienes imponen las preguntas; realiza el imaginario de vidas diversas, fugadas de la soberanía y de

\footnotetext{
${ }^{5}$ Los linajes biográficos forman un mapa trans al realizarse en el imaginario, ignorando la exhortación de Borges en "El escritor argentino y la tradición" a "creer en la posibilidad de ser argentinos sin abundar en color local" (Borges, Discusión 157). En Copi todo color se deslocaliza, y a lo sumo habilita la creencia en la posibilidad de ser argentinos marginales, "de París" o "uruguayos". La alternativa clásica para reorganizar la tradición sustrayéndola del canon nacionalista hegemónico -reconocer como propia "toda la cultura occidental"- se enriquece por el plus de marginalidad que Borges asigna a la cultura sudamericana: como a los judíos con respecto a Occidente y a los irlandeses con respecto a Inglaterra, a los argentinos debería resultarnos "más fácil (...) innovar en la cultura", "manejar todos los temas europeos ( ...) sin supersticiones", con "irreverencia" (160-161). La lógica transnacional de Copi habilita una marginalidad impensada: tan luego de Borges, devenir uruguayo puede facilitar otras innovaciones y una irreverencia profanadora.
} 
toda tarea suprema, ajenas a la equivalencia entre nacimiento y nación y a los símbolos asociados. Para la opinión pública argentina hace algo peor que denigrar a su patria: se ríe y a la vez llora, pero ni siquiera de o por la patria (porque tal cosa ya no existe, o qué catzo importa), sino de la catástrofe humana y porque (como titula en francés su genial novela de 1979) "la vida es un tango" -repetido, como veremos, por un loro compadrito-. Copi deshabita el canon territorial, nativista, desoculta la imposición cultural bajo lo que se considera natural y nativo. Cuando la institución literaria redefina sus fronteras en las dos décadas siguientes a la última dictadura, le será difícil hacerle lugar a este átopos tan fascinante como inasimilable; hasta entrado el siglo XXI Copi parecería un fantasma no territorializable, pasible de apariciones laterales no sistemáticas. ${ }^{6}$

Es lógico que Copi falte de un campo intelectual que, tras dos décadas de democracia luego de cinco de inestabilidad golpista cívico-militar, parece saturado de consenso y temeroso de alterar el paradigma de orden (neoliberal). Copi es lo que falta porque sobra, es el exceso de una falta, la puesta en escena exagerada de voces disonantes, la impura acción del malentendido literario, que "se ejerce en detrimento del mismo paradigma de orden que el desacuerdo político: el bello animal, compuesto como una armonía de miembros y de funciones en una totalidad orgánica" (Ranciére 69). La escena fragmentada e

\footnotetext{
${ }^{6}$ Valga un ejemplo de la atopía de Copi en el campo literario contemporáneo. De las veinte intervenciones publicadas en Lo que sobra y lo que falta (en los últimos veinte años de la literatura argentina) -ciclo de mesas redondas con escritores y críticos organizadas por el Centro Cultural Ricardo Rojas en marzo de 2004- solo tres hacen sitio a Copi. En dos casos se trata de menciones que lo incluyen en distintos tipos de serie: Astutti rescata a Puig, Copi y Perlongher de la exclusión de una zona en la que los tres se incluirían ("el melodrama y el kitsch y el camp y el neobarroco y la literatura gay") (AAVV, Lo que sobra 54); Gamerro entiende que a su generación (nacidos en los primeros 60) le "faltan padres" ya que "los escritores con los que nos podríamos haber peleado" murieron jóvenes o asesinados por la dictadura ("Walsh, Conti, Di Benedetto, Puig, Copi, Osvaldo Lamborghini, Perlongher") "a lo que se sumó el retraso temporal" de no haber podido leer a la mayoría hasta 1983; aunque con otra fundamentación, la serie de Gamerro incluye, dispersa, la de Astutti, y en ambas Copi es un nombre dicho al pasar, incluido en cierta configuración genérica de visibilidad incipiente, opacada por Piglia y Saer, "los únicos de peso que nos han quedado" (64-65). Desplazando esa dupla canónica en beneficio de otros dos "centros de la literatura argentina contemporánea" que serían Aira y Carrera, Link conecta el vértigo que Aira lee en L. V. Mansilla con la velocidad que "reconoce como virtud de Lamborghini y Copi" (118-120).
} 
inorgánica de La sombra de Wenceslao, atravesada por relaciones que exceden lo humano, realiza una comunidad flotante susceptible -en términos de Ranciére"de formar nuevas ficciones, que dividen al todo, que deshacen su forma y su funcionalidad". El malentendido es exceso en tanto introduce otro cálculo que deshace el ajuste proporcional de los cuerpos a los significados, suspende las formas de individualidad de esa lógica consensual. En la aduana literaria legislada con categorías previamente definidas (novelista, dramaturgo, parodia o sensibilidad camp) Copi pasa de contrabando un disenso que deshace las correspondencias establecidas.

La acción que movilizan los personajes es excesiva, una sobra inutilizable, un residuo que siempre faltará de la materia aprovechable como "literatura argentina”. De ahí que -al contrario de lo que propone Amícola rehaciendo las correspondencias entre autor y literatura nacional- antes que pedir su "repatriación literaria" sea más impertinente y productiva la otra opción, seguir preguntándose "a qué literatura pertenecía Copi", o mejor, cómo hizo para des-pertenecer de toda literatura. Más allá de que pueda citarse a "su madre, entrevistada por mí" como fuente para probar que "Copi se sentía parte de la literatura argentina" (Amícola), sus textos abren diversas preguntas sobre esa literatura de atributo nacional, dejan recuperar partes desconectadas de la Biblioteca Argentina, ${ }^{7}$ ver lo que queda en movimiento de una tradición plagada de estereotipos cuando se la libera de ellos y se los pone a funcionar de otra manera, en paisajes impensados, entre el pasado histórico y un futuro de catástrofe: "La literatura trabaja desde el residuo para provocar sorpresas en nuestras conexiones asociativas normales entre acontecimientos históricos. Su objetivo es provocar perspectivas diferentes de ciudadanía y acción" (Masiello 299). Aunque el teatro de Copi no "trabaja" para producir nada ni cabe en ningún listado de "objetivos", sí parece dispuesto a provocar sorpresas y perspectivas diferentes, como un residuo benéfico, ante la

\footnotetext{
${ }^{7}$ Tomo el sintagma Biblioteca Argentina de Libertella, quien lo usa para invertir esa "especie de unción hacia los antepasados, (...), la rutina casi antropofágica de querer 'comerles' su estilo, su persona, su genio": "ipero si Argentina es exactamente al revés; no las lecturas comunes de una tradición, sino una tradición de lectura!" (Libertella 28; subrayado en original).
} 
CATEDRAL TOMADA: Revista literaria latinoamericana / Journal of Latin American Literary Criticism

El escritor uruguayo y la imaginación. Una tragedia bárbara de Copi en argentino

fijeza montañosa de lo nacional, donde cavar un pozo propio y seguir siendo excesivo, profanador, inapropiable.

\section{La montaña y el pozo}

Yo tengo siempre el mismo lugar: un gran agujero que cavé en la arena y en el que coloqué algunos efectos personales e incluso un tocadiscos de pilas.

(Copi, El uruguayo)

Si no hace falta consultar el frondoso archivo gauchesco para leer Cachafaz o Wenceslao, la experiencia (lectora o espectadora, emancipada y activa según exige Copi) torna grata y renovada la vuelta al repertorio gauchi-malevocriollista de lo argentino, funcional tanto en los inicios de la modernización agroexportadora hacia 1880 , como en la cultura posindustrial y transnacional que emerge un siglo después. Algunos mojones de la serie fuerte y masculina de la canónica literaria argentina mostrarán la supuesta montaña a la que Copi propone no subir.

Hacia 1910, la crítica institucional demarca las fronteras de la lengua y legisla sobre el reparto de sonoridad en el escenario nacional: traza el espacio habitable de la república de las letras, dejando afuera el desierto, lo inhabitable, los no habitantes, los no nativos, los extranjeros. Lo hace echando mano a los imaginarios discursivos que integrarían, en el nuevo territorio poblado de ganados y mieses, aquel peligro pasado devenido símbolo, el gaucho como un fantasma reterritorializado, Martín Fierro cantor o sus sombras posteriores. En años en que brilla en escena la pregunta “¿Qué somos los argentinos?” (y pululan entretenidas respuestas), estratégicamente emocionado por las fiestas patrias del Centenario de la Revolución de Mayo y la Independencia (1810-1816), el consagrado poeta 
Lugones asume el encargo del Consejo Nacional de Educación y celebra la historia argentina, condensándola en su Historia de Sarmiento, publicada por el Estado en 1911. El poeta nacional enriquece su estudio abundando en Andes, Alpes (el modelo es Europa occidental), moles, montañas y otros símiles geológicos, equivalentes a la "grandeza atormentada" de Sarmiento, ese "hombre andino" con "perfil histórico de gigante" (Lugones, Historia 255). Con el aplauso oficial, el poeta se empeña, persiste y, en el furor de celebrar un nosotros adecuado, entronca al gaucho (no cualquiera: solo la mole mestiza y desparecida, Fierro) en el árbol derecho y bien podado que planta como raíz de una literatura que deberá tener, mejor que la espesura de una selva, la calma de un parque urbano. En seis conferencias pronunciadas en 1913 en el teatro Odeón de Buenos Aires, a partir de las cuales elabora en 1916 El payador, Lugones coloca al Martín Fierro la chapa de "libro nacional de los argentinos". ${ }^{8}$ Iniciando una conexión que será duradera, afirma que es fácil hallar en el gaucho, esa "sub-raza mestiza de transición", "el prototipo del argentino actual": "el fondo contradictorio y romántico de nuestro carácter", "la sensibilidad musical", "la importancia que damos al valor", "la jactancia, la inconstancia, la falta de escrúpulos para adquirir" (Lugones, El payador 61, 66). El gaucho ha desaparecido, "para bien del país", pero su definición como tipo nacional nos ofrece un carácter (masculino) de apropiada cepa criolla.

El terreno era abonado en 1912, también con la legitimación estataleducativa, por Rojas al inaugurar en la Universidad de Buenos Aires la cátedra de Literatura Argentina, en cuya presentación, como en los tomos de la Historia de la literatura argentina que publica entre 1917 y 1922, el prestigioso docente e investigador canoniza la literatura gauchesca como "roca primordial" de la

\footnotetext{
${ }^{8}$ En medio de una erudita operación humanista que recupera lo clásico de la cultura europea, El payador destaca la actuación del gaucho en las guerras del siglo XIX, considerándolo "héroe civilizador de la Pampa”, depositario de una imagen homogénea de la ciudadanía, necesaria contra la peligrosa mezcla del "aluvión" inmigratorio. A diferencia de Rojas, Lugones separa el poema de Hernández de la gauchesca anterior: exagerando la nobleza de ese "hijo de la pampa", lo distingue de aquel "mísero comienzo" con Hidalgo, del "poeta falso" Ascasubi cuyo gaucho es corrompido y ridículo, y del "disparatado" Fausto criollo que se ríe y hace reír "a costa de cierto gaucho imposible" (Lugones, El payador 135).
} 
CATEDRAL TOMADA: Revista literaria latinoamericana / Journal of Latin American Literary Criticism El escritor uruguayo y la imaginación. Una tragedia bárbara de Copi en argentino

materia (Rojas 58). En la tarea clasificatoria de conformar lo que faltaba (un canon nacional, obras clásicas propias, estudios bibliográficos: la literatura argentina), todos los vectores de la tradición como monumento confluyen en la elección del gaucho como arquetipo, “en quien jamás claudican ni el honor individual ni el patriotismo que se funda en el instintivo amor a su tierra", rasgos que ostentaría el Martín Fierro como "epopeya de una república de pastores". Inventando la literatura nacional con el apoyo en la "ley biológica", como "un todo orgánico" que expresa "el alma argentina" (Rojas 65), la primera historia de la literatura argentina establece una conexión, que será hegemónica, entre dos series conflictivas de la organización moderna de una comunidad nacional: el gaucho (sujeto nómade territorializado por jefes militares, patrones estancieros, críticos y profesores de literatura) y la república (democrática hasta incluir a los pastores: gauchos sedentarios, domesticados). Entre Rojas y Lugones se ha establecido la norma correctiva de lo que, al estudiar el criollismo en la formación de la Argentina moderna, Prieto ve como superficie de lo gauchesco, su rol aglutinante de usos expresivos correspondientes a una tipología social marginada de la ley y el orden.

Discutiendo con Lugones y Rojas, y entre sí, hacia mediados del XX Borges y Martínez Estrada vuelven a escribir sobre la montaña, para demolerla y construir territorios propios. Aparecido en 1948, Muerte y transfiguración de Martín Fierro, autocalificado "ensayo de interpretación de la vida argentina", es un cuestionamiento completo de esa tradición que convertía al gaucho en arquetipo nacional y neutralizaba el carácter revulsivo de su denuncia. Pese a su potencia crítica (o debido a ella) el libro de Martínez Estrada deviene pronto monumento, ladrillo silencioso en la cultura literaria argentina dominada por la palabra de Borges, hasta que es reeditado y revaluado en fin de siglo. Desde la década del 30 en artículos publicados en Sur y otras revistas, y en conferencias y prólogos durante toda su carrera, Borges interviene con su veta polemista en el campo de debates sobre el gaucho y la gauchesca, tomando distancia del nacionalismo cultural y del peronismo, cuya vuelta al poder a comienzos de los 70 
crispará su lectura del clásico de Hernández y reactivará la dicotomía sarmientina (cf. Borges, Prólogos 99, 133, 139). En el librito dedicado al Martín Fierro en 1953, Borges advierte contra el riesgo festejar su violencia: la escena del duelo con el Moreno -en El gaucho Martín Fierro (1872), cuando el héroe se emborracha, provoca y mata a un inocente- "merece su fama", pero "desgraciadamente para los argentinos, es leída con indulgencia o con admiración, y no con horror" (Borges, El Martín Fierro 57). Aunque en las ficciones heroicas de sus comienzos Borges entronca la vanguardia con el criollismo y explora la violencia del duelo y el culto al coraje, la lectura canónica borgeana no dejará de señalar esa perniciosa influencia que Prieto analiza en la recepción del criollismo en las primeras décadas del XX.

Otra política de rescritura de la gauchesca, liberada de la moral de lectura, sostiene el poeta Leónidas Lamborghini: en entrevistas, ensayos y algún seminario universitario hacia el fin de siglo, y en ciertas zonas de su poesía antilírica desde la década del 50, desarma el modelo y distorsiona la lengua de los clásicos. Como Borges con respecto a Lugones, Lamborghini se aleja de la versión mítica nacionalista del gaucho, pero a la vez recupera el costado irreverente que molestaba a Borges y mantiene activa la lectura peronista de la dicotomía para invertirla. Destaca lo payasesco y revulsivo de Fierro, desmitificando al personaje que sería un tragicómico bufón con chiripá, un cuchillero cebado y racista que invade el lugar del Héroe Clásico: "Los argentinos tenemos un Héroe Nacional que es eso, un cuchillero", que encarna el eje de nuestra historia: "la frustración, la derrota" (Lamborghini, "El gauchesco" 108109). ${ }^{9}$ Por los años en que Copi pone gauchos en escena, el prejuicio lugoniano y

${ }^{9}$ En los poemas que van de El Saboteador Arrepentido (1955) a El Solicitante Descolocado (1971) se teje una serie que el autor llama gauchesco urbano: "una gauchesca sin gaucho, sin caballo, sin boleadoras", pero con esa distorsión política y lingüística del Modelo que es, para Lamborghini, "el espíritu de la gauchesca". En El riseñor (1975) retoma las grandes voces de la payada entre Fierro y el Moreno (el canto 30 de La vuelta de Martín Fierro de Hernández, 1879), las desacopla y minimaliza, convirtiendo aquella sabiduría exhibida en sintaxis quebrada, donde la payada se reduce a un balbuceo entre dos sabios, "el Sabio Blanco y el Sabio Negro", que se experimentan mutuamente. Durante su exilio en México (1977-1990), Lamborghini escribe una serie de textos relacionados con la gauchesca anterior a Hernández, donde practica su distorsión 
CATEDRAL TomAdA: Revista literaria latinoamericana / Journal of Latin American Literary Criticism El escritor uruguayo y la imaginación. Una tragedia bárbara de Copi en argentino

la lectura moral borgeana ya han sido superados por la posibilidad de reír ante la tragedia, no a costa de (como criticaba Lugones en el Fausto) sino junto con "cierto gaucho imposible", que provoca mucho más que el horror o la admiración de la sarmientina afectividad de Borges. Y aunque la distancia irreverente se parece al gesto lamborghiniano, también aquí Copi se corta solo, no parodia un modelo porque no hay tal: desconoce el derecho de propiedad sobre cuya rescritura trabaja Lamborghini, y usa de hecho los cuerpos deshechos de ese santoral.

Ante el archivo rocalloso (como adjetiva Lugones el aspecto de Sarmiento), Copi cava un pozo, elige no subir y poner en acción su no subida, ver la montaña desde abajo o ver lo que habría si no estuviera la montaña. En su acción narrativa deja de haber una continuidad sobre la cual operar alguna ruptura o un modelo al cual parodiar o transgredir, porque desoye la demanda de la tradición, porque ante ese modo pensar el arte dice simplemente "no sé qué responder". Bajo la sombra docente de Lugones, con grados diversos de virulencia y disenso, Borges, Martínez Estrada, Lamborghini -envueltos en el mismo misterio del que fuga familiarmente Copi, el peronismo- han operado sobre el canon (re)conociéndolo previamente. Las lecturas de la gauchesca y de la tradición nacional comienzan a leerse a sí mismas en las últimas décadas del XX, aunque mantienen, como en el clásico tratado de Ludmer en 1988, la cuestión de la patria en el centro del género y, así sea para volverla dinámica y maleable, se ubican en diálogo con la tradición. Si Lamborghini tiene su lugar en ese "tratado sobre la patria", el caso de Copi parece irreductible a relecturas tramadas en la institución universitaria (de Rojas a Ludmer). Ante el consenso crítico, la lógica de Copi promueve un disenso inagotable e inutilizable, suspendiendo toda adhesión en un movimiento menos transgresor que profanador. Tan externo a la 
biblioteca posborgeana como a la antilírica de Lamborghini, Copi rechaza la identificación con una lengua y con un territorio: esquiva el estilo por vía de la imaginación, y se fuga de la tradición mediante guapos transnacionales envueltos en la peripecia de realizar lo imaginario. A las ficciones guerreras del EstadoNación, el universo-Copi les opone "la idea de comunidad (posnacional y, al mismo tiempo, imposible)" (Link, "Santa Copi").

$\mathrm{Si}$ el gaucho arquetípico ofrecía la base geológica de una identidad homogénea y robusta para la comunidad nacional (atravesada por lo extranjero percibido por Lugones como "aluvión zoológico"), el gaucho posnacional y entrópico cava un pozo donde la cultura y la lengua exhiben e incumplen el presunto contrato natural de la comunidad. Tal contrato no contiene las leyes de la naturaleza sino las "leyes culturales de nuestra comunidad de nacimiento", desde que "la naturaleza no existe más que cultivada por una cultura y por un culto, cantada por una lengua, contada por un cuento" (Pardo 262-263, 267). Dejando en ridículo los debates sobre la argentinidad y los cultivos humanistas y nativistas que se apropiaron del suelo pampeano y su pingüe patrimonio cultural y económico, los gauchos de Copi activan una intervención posible sobre el archivo nacional que asimiló al gaucho como símbolo cultural de un "ser argentino" (emanado del suelo en su origen y vuelto sombra en sus finales). Símbolo y naturaleza no alcanzarán a encerrar a Wenceslao en su intrascendente travesía de risa y muerte; el dispositivo Copi corta la persistencia de la cultura, que "consiste en reconstruir constantemente su territorio y en repetir constantemente su temporalidad propia, en reproducir constantemente sus imágenes características" (Pardo 276). Lo notable de Wenceslao y Cachafaz es que con ellos el dispositivo actúa sobre lo más duro y persistente de esos cuentos y cantos que traman la cultura argentina. Si "los límites de una cultura son los límites de su posibilidad de traducir e interpretar", la escena de Copi se arma en el desquicio de esos límites; y si "la representación es la estrategia mediante la cual la existencia se reproduce" y todo puede ser interpretado/traducido según "los términos establecidos por las imágenes que cada cultura es", la acción de Copi muestra que 
CATEDRAL TOMADA: Revista literaria latinoamericana / Journal of Latin American Literary Criticism El escritor uruguayo y la imaginación. Una tragedia bárbara de Copi en argentino

no hay representación ni nada que interpretar, y que las imágenes pueden profanarse para que la cultura deje de ser y pase a devenir (Pardo 277; subrayado en original).

El desquicio y la negativa a representar son modos de desmesurar lo argentino, fugarse a patrias imaginarias realizadas en el Uruguay del Uruguayo y de Wenceslao, profanar la " ¡Bendita Argentina!”, desterritorializar el país como Magallanes al final de "Río de la Plata", cuando para seguir la trayectoria de la Luna en el Mar considera "necesario que las tierras no existieran" (Copi, Obras 358). Porque las tierras existen (y son materia de ciencias, mapas, guerras) Copi desentona en todo canon, así sea de lo alternativo o la transgresión, y se sustrae de esa continuidad con rupturas que la institución establece como literatura argentina. Bajo la sombra de esa mole trazada entre Lugones y Borges, cuesta percibir la seriedad y potencia de postulados políticos y antropológicos disfrazados de una gracia infinita, como las conexiones trazadas en la comunidad inviable de Wenceslao, entre animal/humano, hombre/mujer, padre/madre/hijos/hermanos (cruza mestiza contaminada por la profanación de lo sagrado). La "reflexión conjunta sobre la categorización de lo viviente (...) y la soberanía política (...) es el rasgo menos comprendido de la obra de Copi" (Link, "Santa Copi"), que indagaremos en el periplo realizado en zona criollista por los personajes de La sombra de Wenceslao. 


\section{Un gaucho uruguayo}

¿Ve como tenía razón al pedirle que tachara todo?: el Uruguay ha cambiado de repente tanto que lo que hasta ahora le he contado ha quedado caduco.

(Copi, El uruguayo)

El gaucho puede ser imaginado omitiendo lo prestigioso, a trasmano de Lugones y los monumentos, recuperando lo pintoresco de distinto modo que los nativistas, folcloristas e imitadores mediáticos que pululan hasta hoy, e incluso reponiendo, sin parodia, lo revulsivo y ominoso que implicó su cuerpo y su voz escrita en la cultura pre-nacional, anterior a la modernidad fundadora del Estado argentino a mediados del XIX. El "nacimiento" del gaucho ha querido ubicarse en el supuesto "contrato natural" (orden jurídico que diferencia del extranjero al "hijo del país") cultivado, cantado y contado por el nacionalismo cultural hegemónico. Copi permite pensar esa zona ambigua -el desierto sin ley donde el derecho abarca lo viviente- a la manera del foucaultiano nacimiento del homosexual: "la homosexualidad (...) llegó a ser un problema a partir del siglo XVIII (...) con la policía y el sistema jurídico” (Foucault, Dichos 205). Si la psiquiatría controla, clasifica y nombra la homosexualidad para arrinconarla en la sección patológica de las perversiones, también gaucho fue, entre los siglos XVIII y XIX, la clasificación de una subjetividad externa a la norma y peligrosa para el orden, en el momento histórico en que, según Foucault (que señala el siglo XVII para el ámbito europeo), los discursos entran en "la edad de la represión", y lo viviente comienza a ser distribuido en un dominio de valor y de utilidad, en el que al hombre moderno le cabe la definición pos-aristotélica: "un animal en cuya política está puesta en entredicho su vida de ser viviente" (Foucault, Historia 11, $135)$.

Interpelado por esa nueva definición biopolítica que lo encasilla en su condición viviente (animal, no humano), el gaucho a la vez mantiene restos atávicos del sujeto desaparecido por el moderno sistema penal "justicia-policía- 
CATEDRAL Tomada: Revista literaria latinoamericana / Journal of Latin American Literary Criticism El escritor uruguayo y la imaginación. Una tragedia bárbara de Copi en argentino

prisión” afianzado a fines del XIX (junto, en las pampas, al moderno sistema económico "trabajo-patrón-estancia", donde se integra el gaucho de Ricardo Güiraldes en Don Segundo Sombra de 1926). La descripción arqueológica de ese sistema que hace Foucault podría implicar a gauchos bandidos como Juan Moreira (héroe folletinesco de Eduardo Gutiérrez en 1880, que pasa vertiginosamente al circo y al teatro, y luego al cine y la televisión) y matreros como el Fierro de la Ida (El gaucho Martín Fierro de Hernández), a quienes la ley convierte en delincuentes: la penalización se dirigía especialmente "a los elementos más nómadas, a los más inquietos, a los 'violentos' de la plebe", “gentes 'peligrosas' que era preciso poner aparte (...) para que no pudiesen servir de punta de lanza en los movimientos de resistencia popular" (Foucault, Microfisica 57-58). El linaje de Moreira, con las populares bajezas del folletín y las perversiones criollistas, alcanza a Wenceslao más intensamente que la línea prestigiosa, higiénica y libresca del Fierro que en 1879 acepta el orden estatal, se enmienda y vuelve porque "el trabajar es la ley" y "es preciso alquirir" (Hernández, La vuelta de Martín Fierro). Y si Fierro o Moreira cabían en el estereotipo lugoniano de la "jactancia" y "falta de escrúpulos para adquirir", Wenceslao, con su infantil orgullo de macho servido por mujeres, no puede ser captado en ninguna caracterización positiva.

Junto con variantes peyorativas como gauderio, changador o mozo vagamundo, la voz gaucho sirvió para "señalar a un grupo humano bien definido": los hombres mestizos, en general solteros y jóvenes, que desde 1600 habían empezado a alejarse hacia la campaña, donde la abundancia de ganado cimarrón ofrecía la posibilidad de subsistir sin trabajar (cf. Rodríguez Molas 7374 y otras). Al sustraerse de dos formas represivas, el trabajo legal y el SistemaFamilia, el gaucho propiciaba la espontaneidad del ritmo personal de la vida, esa "configuración sin fijeza ni necesidad natural", la "idiorritmia" en torno a la cual Barthes (de modo muy contemporáneo a Copi) piensa sin contradicción cómo querer estar solos y vivir juntos (Barthes, Cómo vivir juntos 48, 50-52). La acción de La sombra de Wenceslao desbloquea el Sistema-Familia en una errancia que 
carece de necesidad natural tanto como de final feliz, accionando diversos sentidos de la idiorritmia gaucha, difusos de tan amplios, transversalmente relacionados con la vida nómade, en un espacio que la ley y el orden controlan en el último cuarto del siglo XIX. La obra transcurre en la década de 1940, mucho después de la solución final del problema gaucho (con la inmigración y la modernización del campo desde la década de 1860), y después también de la reactivación espectacular de su símbolo en la industria criollista, cuando sus restos arman cuerpos de gauchos alzados, malevos y guapos orilleros, que impulsan la modernización cultural en las primeras décadas del XX. Wenceslao es un gaucho postrero, anacrónico, en una intempestiva modificación temporal que acompaña la alteración geopolítica de su devenir uruguayo.

Escrita en la variedad dialectal rioplatense del español -excepcional (junto con Cachafaz) en la obra de Copi mayormente escrita en francés-, estrenada en el Festival de la Rochelle en julio de 1978, La sombra de Wenceslao compone conexiones plurales, no lineales, entre heterogéneos seres vivientes. Además de los animales (loro, caballo, mono) y de la lluvia y el viento, que intervienen en la acción, entre los personajes humanos podrían trazarse dos tríos inestables, con intercambios apenas controlados: Wenceslao-Mechita-Largui / Rogelio-ChinaLargui. Los parentescos son cruzados, a partir de la paternidad nómade de Wenceslao: su hijo legítimo Luis ni aparece, porque la madre (Hortensia) "lo mandó a estudiar a Buenos Aires", y según este gaucho homofóbico (hijo putativo del caballero lugoniano) "me salió un compadrito" marica (Copi, Cachafaz / La sombra 78). Rogelio es el presunto hijo que Wenceslao tuvo con Mechita, aunque en el primer intercambio entre ambos, sin ningún asidero Wenceslao sospecha de Largui, le dice a Rogelio “¡Tu madre es una puta!”, y aunque Rogelio insiste en que es hijo suyo, el precario padre responde "Mirá, muchacho, ¡no estoy tan seguro!" (79-80). Otra vez las filiaciones titubean cuando Rogelio, para defender su noviazgo con la China, hija de Wenceslao, desestima los lazos biológicos: "iQué va a ser mi hermana, don Wenceslao! ¡Si no nos hemos criado juntos!” (83). En paralelo inexacto (porque se tocan, se toquetean) mientras Wenceslao se 
abalanza sobre Mechita, Rogelio convence a China de que no son hermanos porque él es hijo de Largui: usa la sospecha que le rebatía a Wenceslao ("soy hijo tuyo") como verdad desmentida en favor de su conquista erótica ("soy hijo de Largui”: no hay incesto). La herencia se acomoda según las conveniencias, algo que a su modo hicieron en la esfera pública quienes, hacia 1910 y después, enraizaron el árbol argentino en el gaucho, y lo mantuvieron podado cuando las ramas crecían desordenadamente.

En Copi las filiaciones no son por conveniencia ni la tradición funciona como arte de la poda: la realidad objetiva es soberanamente ignorada, con la fuerza de ese sistema móvil de relaciones que es el teatro. La acción no se deja atrapar en la zona entrerriana de Diamante donde ocurre el primer acto, aunque se trate de la prestigiosa geografía originaria del gaucho argentino-uruguayo, según gauchistas anti-porteños como Emilio Coni. ${ }^{10}$ El dispositivo teatral funciona en esa geografía de la argentinidad corrida del centro, aunque su traslado será opuesto al del gaucho de Coni: si este se extendía de Santa Fe hacia Entre Ríos, Uruguay y la región pampeana, Wenceslao sacará su carreta del pantano entrerriano para subir hacia las Cataratas del Iguazú, húmeda y múltiple frontera de la nación, selva de la mezcla, el contrabando, el turismo y el softcore local. ${ }^{11} \mathrm{Si}$ la carreta, empantanada por ese personaje molesto que es la lluvia, permitirá la fuga hacia la utopía del Iguazú, el otro espacio de acción del primer acto es fijo y femenino, a resguardo del clima pero no de la "naturaleza masculina": en el "Interior de la Mechita" (según didascalia) el gaucho desplegará exageradamente lo que Lugones celebraba como "el fondo contradictorio y romántico de nuestro

\footnotetext{
10 Menos documentado en los archivos coloniales citados que en impresiones de viajes agronómicos y turísticos, la tesis que alienta Coni en El gaucho cuestiona la mitificación apropiadora realizada por la cultura porteña (del área metropolitana de Buenos Aires) y procura desarmar lo que llama "dogma gauchi-pampeano", inventado por la "miopía porteña que ignora la existencia argentina del bosque y de la montaña porque no se divisan desde los rascacielos de la metrópoli". El remate lo da el último subtítulo: "Las verdaderas tradiciones argentinas no están en la pampa cosmopolita" (Coni 303-304, 320).

${ }^{11}$ Además del spot de jabón, filmado en las Cataratas del Iguazú, que cuidaba lo mostrable de la piel de Susana Giménez, pueden consultarse las películas que Isabel Sarli filmó en la zona misionera-paraguaya en la década del 60, nacionalizando las bellezas con mirada de varón.
} 
carácter" y "la importancia que damos al valor", desarmando esa impostada masculinidad guerrera. El loro replica la oscilación de los machos del trío, y anticipa a quién preferirá Mechita según otras connotaciones del postulado fondo romántico varonil: “¡Wenceslao pija “e palo!” - “iViejo Largui pija blanda!” (Copi, Cachafaz / La sombra 89, 98). Al contrario de "la castidad" que Rojas celebra en la relación de Fierro con la cautiva en la Vuelta, Wenceslao no hace sino turbar "la ley del honor caballeresco por el interés de una compensación sexual" (Rojas 543). Si Largui pide la mano de Mechita, el macho verdadero, rebenque en mano y alentado por el loro compadrito, corporiza su conquista en otros órganos: “¡Qué mano ni qué mano! ¡Yo te rompo la concha!” (Copi, Cachafaz / La sombra 99). Contra la poda represiva, Wenceslao y su loro replicante exaltan lo reprimido en la gauchesca culminada por Hernández y celebrada con honor viril por Lugones y con romanticismo castizo por Rojas: la sexualidad, donde principalmente se aplica el "poder médico judicial" de normalización (Foucault, Los anormales 49). Las interacciones de los tres hombres con las dos mujeres, además de desarticular conexiones familiarmente apropiadas, desocultan el cruce de categorías de ciudadanía que Masiello lee (en el travestismo literario de Diamela Eltit) como desenmascaramiento de la "carga masculina atribuida a las visiones heroicas", denunciando "como igualmente sospechoso cualquier otro intento de fijar una identidad bajo la ley del Estado" (Masiello 209).

Exagerando las máscaras y riendo sin denuncia, la obra reutiliza, de hecho y sin derecho, los tópicos de género nacional. Ante la pareja formada en el desmentido conveniente del incesto, Wenceslao -salvajemente victorioso en lo que Lugones llama requiebros del galán, el varón como “el esperado del destino nupcial" (El payador 62-63)- expone a la China su autoridad de "hombre de la casa": "Vos podés casarte con quien querrás, pero ahora mismo me vas a hacer un asado" (Copi, Cachafaz / La sombra 112). Luego de obligar a la hija a bañarlo, da su bendición a la pareja pero tiene algo más (y mejor) que anunciar, su intempestivo devenir uruguayo: "Me voy pa'l Norte. (...). Pa'l lado del éxodo del 
viejo Artigas" (115). La lluvia propicia el desbande, cuando el "viejo Paraná traicionero" desborda y desterritorializa lo que no llegaba a ser una comunidad. En el segundo acto la acción se acelera y nomadiza, alternando en un montaje regional tres zonas heterogéneas de la geografía argentina. Las fugas serán diversas, a las cataratas una y a la ciudad otra, ambas hacia la catástrofe antropológica que, como en El uruguayo, excede la crisis política. Wenceslao, el loro y Mechita van al Norte en la carreta bajo el temporal. El trío Rogelio-ChinaLargui se instala en el "interior de casita en Paraná", pero no dura mucho: el deseo de ver a Mechita impulsa a Largui en bicicleta, "con los catorce pesos que me quedan" (146), en un viaje de horror y chiste hacia las Cataratas del Iguazú. ${ }^{12}$

La fuga imposible a la gran ciudad será motivada menos por el progreso profesional de Rogelio que por el estereotipo femenino, el embelesamiento de China ante la cultura industrial emanada de Buenos Aires y reproducida por la voz radial de Tita Merello (como Sandrini, estrellas del espectáculo nacional desde la década de 1930). Luego de volver a ser un trío en la casita de Paraná (cuando nace un hijo, que tampoco dura mucho: los venenos están siempre al alcance de inocentes, y el colmo de la lluvia ofrece un remate de chiste $)^{13}$ Rogelio y China van directo a la catástrofe porteña. En sitios fronterizos como la estación Retiro, la argentinidad se pone vertiginosa y el derrumbe llega voceado por el canillita, ofreciendo el diario Crítica "con todos los crímenes". Tras el revés en su carrera política (Perón obtuvo la Presidencia) Rogelio se acomoda a los nuevos

\footnotetext{
${ }^{12}$ La fuga de Largui hacia la furia de la naturaleza ofrece memorables escenas (19 y 21) en una secuencia "cómica cómica, como las de Sandrini”, según las filias de Copi (Tcherkaski 82). "Se me pinchó la goma y perdí el inflador. ¡Qué solazo, Dios me libre! (...). Ya no me queda casi nada del salame que compré ayer en la pulpería, y se me acabó la plata" (Copi, Cachafaz / La sombra 150). Tras la elipsis en la cual ha logrado robar una gallina, su situación empeora hasta la risa total: “¿Cuántas leguas me faltarán para las Cataratas del Iguazú? ¡Puta, qué asquerosa que es una gallina cruda! ¡Dios mío, un buitre! ¡Socorro! ¡Socorro! ¡Me ataca un buitre! ¡Socorro! (Sale en bicicleta)" (153). En la escena siguiente Largui llega a la meta, aunque no puede disfrutar de la broma del mono disfrazado de Wenceslao porque el buitre "me arrancó los anteojos en el desierto" (157). Carcajadas menores del terror de la naturaleza posnacional.

13 "CHINA: ¡Le puse el insecticida para las cucarachas en la mamadera pensando que era leche condensada! ¡Corré a buscar al doctor!

ROGELIO: ¡Dios mío! ¡Y justo se largó a llover!” (Copi, Cachafaz / La sombra 152).
} 
tiempos con un puesto en una empresa estatal y casi realiza la fantasía de acercarse al poder (viven en un departamento a dos cuadras del Congreso). La gauchesca imposible, trastornada con el gaucho uruguayo fugado hacia las Cataratas, se yuxtapone con esta mezcla urbana de diarios, espectáculo, política y crímenes, donde los tópicos expresivos del criollismo son replicados, como lee Prieto, por el repertorio gestual de la política en la formación de la Argentina moderna. El desenlace exagera deformada la conexión entre criollismo y política; la acción teatral conduce estas vidas argentinas del espectáculo a la catástrofe, cuando La China, que "se muere por ver revistas", realiza su imaginario (y torna literal la frase). ${ }^{14}$

En "La carreta en las Cataratas del Iguazú" (según didascalia que sitúa el nuevo hogar contra todo sedentarismo) ocurrirá la muerte que faltaba, que sin salirse de su lógica apela no a la crónica política-policial urbana sino a la sombra que vuelve del fantasma shakespereano. La supuesta familia humano-animal de la carreta acoge a Largui; pero en vez de avizorarse una comunidad feliz, Wenceslao ya está pensando en morirse, sin que haya ocurrido nada más que el viaje, la vida. Aunque Mechita le pide que espere ("Bueno, pero no te mueras hoy, Wenceslao. Pensalo hasta mañana"), en la escena 28 el protagonista se ahorca (según la parca didascalia). Y antes emite su autobiografía uruguaya, usando al loro como memoria y registro oral: “ ¡Che, loro! Vos que sos un animal de más resistencia y que te acordás del hablar de la Banda Oriental, registrame lo que voy a decirte". El vértigo de proezas condensadas en diez líneas comienza cuando "a mi casa la degolló la milicia allá por el año 1850” y “me salvé la vida porque me escondí en un pozo" (172). Con un pozo imposible de más de un siglo como lugar de nacimiento, el gaucho descalabra la temporalidad; ha salido del agujero del

\footnotetext{
${ }^{14}$ La bajada a la capital provee lo único que podía esperarse en la lógica de la pieza: política (criolla), corrupción, aceleración, muerte. El desenfreno de la intriga ocurre con la mediación drástica de Coco Pellegrini, porteño canchero y tránsfuga, eximido de la redención por el trabajo que daba su pedagogía al criollismo; en un restaurante de la Recova, este oligarca y proxeneta "hace cagar" (literalmente) a Rogelio y planea poner a la China como prostituta "en el Bajo esta misma noche". Otra vez muy naturalmente en la lógica de Copi, cuando Coco Pellegrini lleva a la China al teatro Tabarís los sorprende un tiroteo, el canillita anuncia “¡Estado de sitio!” y, claro, la China cae muerta (Copi, Cachafaz / La sombra 174-185).
} 
CATEDRAL TOMADA: Revista literaria latinoamericana / Journal of Latin American Literary Criticism El escritor uruguayo y la imaginación. Una tragedia bárbara de Copi en argentino

tiempo de la patria para luego, ahora, irse "desapareciendo" (188). A diferencia del Fierro de Borges y de Martínez Estrada, Wenceslao ya es un gaucho transfigurado, y con la muerte solo viene la "casi segura" posibilidad, tenuemente hamletiana, de que vuelva la sombra.

La ambientación atípica en el sistema Copi (rural en Wenceslao como será conventillera-montevideana en Cachafaz) provee el espacio de una acción vertiginosa donde el imaginario toma cuerpo, realizando un desorden de géneros en los cruces de identidades localizadas pero desnacionalizadas. Al prestigio nacionalista y las ficciones guerreras del Estado, que traman las lecturas de la tradición gauchesca, el dispositivo teatral opone la movilidad y las voces de nuevos cuerpos que deambulan hacia la muerte, como única salida de las comunidades posnacionales (cf. Link, "Santa Copi"). La acción (la ida sin vuelta, cortando a Fierro en plena fuga anarco-nihilista, en 1872) despliega un sistema de relaciones que ignora la realidad objetiva y desarma los agenciamientos nacionales con lo animal y lo territorial. La vuelta posible es hacia la atopía del gaucho, sujeto desclasificado y degenerado de la pre-modernidad argentina, que en el siglo XX fue territorializado al canonizar el Martín Fierro como poema épico nacional y desterritorializado al convertir un género menor en "tratado sobre la patria".

En las dos piezas trans-criollistas de Copi reverberan, con otras intensidades, los restos aprovechables de la mole geológica, ciertos pedazos rotos del ser nacional. Wenceslao y Cachafaz se mueven en los bordes del criollismo (que ya era una fuga de la gauchesca hacia la incipiente industria cultural) tanto como del teatro del absurdo (desviado en el humor simple del chiste de tira o la comicidad a lo Sandrini). Al costado de la consagrada montaña argentina, Wenceslao cava su pozo; deambula transversal y sin línea frente a la monumentalidad erguida, la horizontalidad pampeana y las rectas alternativas a la dupla civilización-barbarie. Con el coraje infantil que acciona Largui en su pedaleo hacia la selva, La sombra de Wenceslao opta por el desierto, la travesía, lo desclasificado, la ida sin vueltas, a fondo, en fuga. La montaña se derrumba por 
la acción catastrófica del pozo; no es solo que Copi impulse la tradición hacia el futuro sino que, como en los finales de sus piezas teatrales, muestra que ese futuro es imaginable como repetición de la catástrofe. De los restos puede obtenerse una imaginación profanadora, que modifica la organización de lo apropiable, que propone usos no consumibles del gaucho en acción, para siempre desapareciendo, muriendo como Wenceslao en la tragedia bárbara de lo argentino y lo humano.

\section{Bibliografía}

AAVV. Lo que sobra y lo que falta (en los últimos veinte años de la literatura argentina). Buenos Aires: Libros del Rojas, 2004. Impreso.

Agamben, Giorgio. "Política del exilio". Archipiélago. Cuadernos de crítica de la cultura (1996): 26-27. Impreso.

Agamben, Giorgio. "Elogio de la profanación” en Profanaciones. Buenos Aires: Adriana Hidalgo, 2005, 97-119. Impreso.

Amícola, José. “Copi y lo nacional”. Actas. I Congreso Regional del Instituto Internacional de Literatura Iberoamericana. 2005.

$<$ http://www.geocities.ws/aularama/ponencias/abc/amicola.htm>. Junio de 2012.

Barthes, Roland. El placer del texto y Lección inaugural de la cátedra de semiología literaria del Collége de France. 1973, 1978. Buenos Aires: Siglo XXI, 2003. Impreso.

Barthes, Roland. Cómo vivir juntos. Simulaciones novelescas de algunos espacios cotidianos. Notas de cursos y seminarios en el Collége de France, 19761977. Buenos Aires: Siglo XXI, 2005. Impreso. 
CATEDRAL TOMADA: Revista literaria latinoamericana / Journal of Latin American Literary Criticism El escritor uruguayo y la imaginación. Una tragedia bárbara de Copi en argentino

Barthes, Roland. Fragmentos de un discurso amoroso. 1977. México D.F.: Siglo XXI, 1996. Impreso.

Borges, Jorge Luis (con Margarita Guerrero). El Martín Fierro. 1953. Buenos Aires: Emecé, 1979. Impreso.

Borges, Jorge Luis. Discusión. Buenos Aires: Emecé, 1964. Impreso.

Borges, Jorge Luis. Prólogos con un prólogo de prólogos. Buenos Aires: Torres Agüero Editor, 1975. Impreso.

Coni, Emilio Angel. El gaucho. Argentina - Brasil - Uruguay. 1945. Buenos Aires: Solar/Hachette, 1969. Impreso.

Copi. Cachafaz / La sombra de Wenceslao. 1978, 1981. Buenos Aires: Adriana Hidalgo editora, 2002. Impreso.

Copi. Obras (Tomo I). Prólogo de María Moreno. Barcelona: Anagrama, 2010. Impreso.

Copi. Teatro 1. Buenos Aires: El Cuenco de Plata, 2011. Impreso.

Foucault, Michel. Microfisica del poder. 1971-1977. Madrid: La Piqueta, 1992. Impreso.

Foucault, Michel. Los anormales. Curso en el College de France (1974-1975). Buenos Aires: Fondo de Cultura Económica, 2008a. Impreso.

Foucault, Michel. Historia de la sexualidad. 1. La voluntad de saber. 1976.

Buenos Aires: Siglo XXI, 2008b. Impreso.

Foucault, Michel. Dichos y escritos (Tomo III). 1982-1984. Madrid: Editora Nacional, 2002. Impreso.

Lamborghini, Leónidas. Tragedias y parodias I. Buenos Aires: Libros de Tierra Firme, 1994. Impreso.

Lamborghini, Leónidas. "El gauchesco como arte bufo" en Julio Schvartzman (dir. vol.). La lucha de los lenguajes, vol. 2 de Noé Jitrik (dir.). Historia crítica de la literatura argentina. Buenos Aires: Emecé, 2003. Impreso. 
Libertella, Héctor. La Librería Argentina. Córdoba: Alción Editora, 2003. Impreso.

Link, Daniel. “Santa Copi”. 2008.

$<$ http://www.pagina12.com.ar/diario/suplementos/soy/1-115-2008-06-

06.html>. Octubre de 2011.

Link, Daniel. "Las fuentes de Copi: crítica y teoría de 'la loca"”. 2011.

$<$ http://www.revistaenie.clarin.com/literatura/Las_fuentes_de_Copi_0_4157 58651.html>. Junio de 2012.

Ludmer, Josefina. El género gauchesco. Un tratado sobre la patria. Buenos Aires: Sudamericana, 1988. Impreso.

Lugones, Leopoldo. Historia de Sarmiento. 1911. Buenos Aires: Eudeba, 1960. Impreso.

Lugones, Leopoldo. El payador. 1916. Buenos Aires: Biblioteca Nacional, 2009. Impreso.

Martínez Estrada, Ezequiel. Muerte y transfiguración de Martín Fierro. Ensayo de interpretación de la vida argentina. 1948. México: Fondo de Cultura Económica, 1958. Impreso.

Masiello, Francine. El arte de la transición. Buenos Aires: Norma, 2001. Impreso.

Pardo, José Luis. La intimidad. Valencia: Pre-textos, 1996. Impreso.

Porrúa, Ana. Variaciones vanguardistas. La poética de Leónidas Lamborghini. Rosario: Beatriz Viterbo, 2001. Impreso.

Prieto, Adolfo. El discurso criollista en la formación de la Argentina moderna. Buenos Aires: Sudamericana, 1988. Impreso.

Ranciére, Jacques. Política de la literatura. Buenos Aires: Libros del Zorzal, 2011. Impreso.

Rodríguez Molas, Ricardo. Historia social del gaucho. Buenos Aires: CEAL, 1994. Impreso. 
CATEDRAL TOMADA: Revista literaria latinoamericana / Journal of Latin American Literary Criticism El escritor uruguayo y la imaginación. Una tragedia bárbara de Copi en argentino

Rojas, Ricardo. Historia de la literatura argentina, 2: Los gauchescos. 1917. Buenos Aires: Losada, 1948. Impreso.

Rosenzvaig, Marcos. Copi: sexo y teatralidad. Buenos Aires: Biblos, 2003. Impreso.

Tcherkaski, José. Habla Copi. Homosexualidad y creación. Buenos Aires: Galerna, 1998. Impreso. 